\title{
Promoting sustainable intensification in precision agriculture: review of decision support systems development and strategies
}

\author{
Jessica Lindblom ${ }^{1}$ Christina Lundström² Magnus Ljung $^{3}$ • \\ Anders Jonsson ${ }^{4}$
}

Published online: 21 December 2016

(C) The Author(s) 2016. This article is published with open access at Springerlink.com

\begin{abstract}
Precision agriculture provides important issues toward a more sustainable agriculture. Many farmers have the necessary technology to operate site-specifically, but they do not use it in practice, and thus available information and communications technology (ICT) systems are not used to their full potential. This paper addresses how to reduce the so-called "problem of implementation", based on the knowledge that participatory approaches during the design and development process is one of the most important factors to frame technology adoption. The development of sustainable ICT systems through theories and methodologies from the fields of human computer interaction and user-centered design (UCD) is presented and an ongoing Swedish project for development of an agricultural decision support system (AgriDSS) for nitrogen fertilization is used as an example to frame the issue. The overreaching aim is to develop AgriDSSs that are sustainable in design as well as through design by stressing the importance of participatory approaches for the successful development of AgriDSSs. The Swedish project has the intention to apply a UCD approach, and some pitfalls on starting to use this way of working is identified as well as some suggestions on how to reduce them through co-learning processes. Despite the challenges presented in this paper, ICT can contribute significantly to long-term sustainable development. Thus, several competences and scientific disciplines need to act in concert to help develop a sustainable development of agriculture via a transdisciplinary approach that can make an impact on society at many levels.
\end{abstract}

Jessica Lindblom

jessica.lindblom@his.se

1 School of Informatics and Interaction Lab, University of Skövde, Skövde, Sweden

2 Department of Urban and Rural Development, Swedish University of Agricultural Sciences, Skara, Sweden

3 National Competence Centre for Advisory Services, Swedish University of Agricultural Sciences, Skara, Sweden

4 Department of Soil and Environment, Swedish University of Agricultural Sciences, Skara, Sweden 
Keywords Agricultural decision support system - User-centered design - Sustainability · Problem of implementation · Co-learning · Transdisciplinarity

\section{Introduction}

The challenges facing agriculture are immense-the agricultural sector is supposed to fulfil several goals and societal values simultaneously (e.g., increased food production, preserving and developing cultural heritage, biodiversity, climate change and recreational values), while at the same time being both sustainable and economically viable on a longterm basis (EU SCAR 2012). Sustainable development has famously been characterized with the wording of the Brundtland Commission (World Commission on Environment and Development 1987) as "development that meets the needs of the present without compromising the ability of future generations to meet their needs" (Huang et al. 2009). The sustainability discourse is commonly based on the idea of three overlapping areas, or pillars, covering environment, economy, and social development (Boström 2012). A generic path to sustainability is to stimulate people to change towards more sustainable practices and behaviours, irrespective of whether it concerns. Environmental sustainability, for example, is concerned with aspects such as renewable resources, reduction of pollution, finding substitutes for non-renewable resources, and sustainable land-use (e.g., Aubert et al. 2012; Daly 1990). A commonly used concept in agricultural research is sustainable intensification, which has the overreaching goal to increase food production from existing farmland while minimizing the pressure on the environment (Garnett et al. 2013). Briefly stated, the concept can be considered as a response to the challenges of the increasing demand for food, feed and energy from a growing global population, in a world where the natural resources are overexploited and used unsustainably. Therefore it has been stated that efforts to 'intensify' biomass production have to be properly aligned to making the process 'sustainable', otherwise the capacity to produce food, feed and energy in the future will be undermined and subsequently may fail (e.g., Caron et al. 2014a, b; Halberg et al. 2015).

At the very core of all changes towards a more sustainable agriculture are the individual decision-makers as the decisions of each farmer will have positive or negative effects on sustainable intensification (Matthews et al. 2008; Van Meensel et al. 2012). In the agricultural sector, it is the farmers who have to transform facts and figures into daily work practices. It has also been argued that an appropriate way to address sustainability aspects in design of interactive technology is to focus on everyday practices and routines (Pierce et al. 2013). Information and communications technology (ICT) is spreading into almost every aspect of people's daily lives, and hence it must integrate sustainability aspects into applications used by people, e.g., features that can stimulate change in practices and behaviours. An important component is decision supporting ICT systems as a mediator in this context, commonly referred to decision support systems (DSS). A DSS is an ICT system that supports either a single decision-maker or a group of decision-makers in making more effective decisions when dealing with unstructured or semi-structured problems (Alenljung 2008). A DSS can either support the decision maker in an on-going decision situation or it can prepare the decision-maker to perform better in the future through decision training (Alenljung 2008).

It is argued by several researchers that agricultural DSS (AgriDSS) can contribute significantly to long-term sustainable development, but yet the role of AgriDSS as both an 
actor and a solution within sustainable development is receiving only limited attention in current research (e.g., Aubert et al. 2012; Korte et al. 2012, 2013). Properly designed, an AgriDSS can promote and scaffold environmentally sustainable lifestyles and decisions of humans (e.g., Hanks et al. 2008; Susi et al. 2015). However, current AgriDSS available to farmers are not used to their full potential and are not adapted to the trade-offs and high complexity characterizing farmers' decision making (e.g., Eastwood et al. 2012; Mackrell et al. 2009; Van Meensel et al. 2012). This has been called the "problem of implementation" (e.g., Mackrell et al. 2009; Matthews et al. 2008; Rossi et al. 2014) within the agricultural domain. The uptake and acceptance are low, partly because existing AgriDSS are based on what scientists and ICT system developers consider as necessary knowledge that should be implemented in the decision support, but in reality they fail to capture the tacit knowledge and practical needs of farmers. Other reasons for the low adoption rate of AgriDSS by farmers are, e.g., a perceived problem of complexity, lack of observability, level of knowledge of the users, lack of confidence, poor user interface design, tedious data input requirements, low adaptation to the farm situation, no frequent information update, lack of incentive to learn and adopt new practices, and the fear of replacing advisors (e.g., Eastwood et al. 2012; Kerr 2004; Rossi et al. 2014; Van Meensel et al. 2012). Thus, there is an obvious gap between research and practice that McCown et al. (2009) define as the "gap of relevance" which has to be bridged, or at least decreased.

Precision agriculture (PA) plays an important role in a sustainable intensification, and it is recognized as a contributor to farming efficiency and environmentally friendly farming practices. Briefly stated, PA is a management concept based on observing, measuring and responding to intra-field variability in crops. PA technology allows crop farmers to recognize variations in the fields and to apply variable rate treatments with a much finer degree of precision than earlier possible. The emergence of PA technology represents a paradigm shift in farming practices: it permits the consideration of the field as a heterogeneous entity that allows for selective treatment instead of a homogenous entity that is treated equally (Aubert et al. 2012). However, the common practice among many crop farmers and their advisors is to regard the fields as homogenous entities leads to suboptimal treatment, which often results in an over- or under-supply of fertilizers and pesticides. Sub-optimal treatment results in considerable costs for farmers and constitutes a major source of environmental pollution, which in the long run does not contribute to sustainable agriculture (Aubert et al. 2012).

In order to perform adequate PA, credible and usable AgriDSS are needed. It should be pointed out that the single unifying predictor of success or failure of an AgriDSS, which has been put forth by multiple authors, is the extent to which the end users are involved in the ICT system development process. The necessity of a user-centered design (UCD) approach has been stressed by, e.g., EIP-Agri Focus group report (2015), Cerf et al. (2012), Măruşter et al. (2008a, b), Matthews et al. (2008), Thorburn et al. (2011), and Van Meensel et al. (2012). User-centered design is an approach within the field of human-computer interaction (HCI), aiming to develop and adapt the ICT system based on the users' needs as well as the context of use, rather than forcing the users to change their behavior to accommodate to the ICT system from a top-down perspective (e.g., Benyon 2014; Dix et al. 2004; Hartson and Pyla 2012; Preece et al. 2002; Rogers et al. 2011). Major shortcomings of today's AgriDSS are a consequence of a lack of understanding of farmers' decision-making in practice as well as their actual needs. These shortcomings need to be addressed in order to accomplish an AgriDSS that considerably facilitates sustainable agriculture in general and PA in particular, aiming for a sustainable intensification (Caronet et al. 2014a, b). 
Hence, several competences, approaches and scientific disciplines need to act in concert to help develop a sustainable agriculture; since the overall trend in agriculture is towards a more complex, technologically-based crop production with increasing regulation and supervision regarding the use of fertilizers, pesticides and other chemicals (e.g., Rossi et al. 2014). Hanks et al. (2008) point out the importance of sustainability for design, focusing on sustainable design (SD) which is the perspective that sustainability can and should have a central focus within UCD and HCI. The focus in SD has since then centered on the dual link between environmental sustainability and ICT by addressing both sustainability through design-how ICT can be used to promote more sustainable behaviors, and sustainability in design - how sustainability can be the governing principle of the design process of the ICT systems themselves (e.g., Hanks et al. 2008; Issa and Isaias 2015).

The paper aims to investigate and discuss "the problem of implementation" and the related "gap of relevance" from a more sustainable trajectory as well as identifying pros and cons in the shift of ICT system design methodology, from a more technology-centred approach to a more user-centred approach in the design, implementation and diffusion of an AgriDSS for computation of variable-rate application (VRA) files for nitrogen fertilization. This paper uses precision agriculture Sweden (POS) AgriDSS development process as an illustrative case to raise these issues, being influenced by an abductive approach (Thagard and Shelley 1997). This provides us with an opportunity to address this process from two different, but complementary perspectives. On the one hand, the agricultural perspective addresses ideas regarding what kind of AgriDSS farmers may need in PA in order to further develop sustainable intensification. On the other hand, the HCI perspective that addresses generic ICT system development methodologies that provide various kinds of user-centred approaches, but lack in-depth experience of the agricultural domain. Both perspectives put sustainability high on the research agenda, and want to reduce the "problem of implementation" and decrease the "gap of relevance" through insuring high usability, i.e., adapting the AgriDSS to the end users' and stakeholders' needs and goals, and the possibility of reaching satisfied users and AgriDSS success increases significantly. The target group for this work is researchers and other stakeholders who have noticed problems in the process of implementing new technology, such as AgriDSSs, in agricultural practice.

The remainder of this paper is structured as follows. The background section provides some identified failures and success factors in AgriDSS that motivates and frames the topics discussed in this paper. Secondly, it briefly presents some experiences from Sweden regarding design and development of PA technology with the focus on optimizing the use of nitrogen in farming practices. The next sections present sustainable ICT, and introduce the concepts of HCI, UCD methodology and how to handle the challenge of the "problem of implementation". Next, some beginners' pitfalls in applying UCD/PD methods and some suggestions on how to reduce them are outlined. The paper ends with a discussion and some conclusions.

\section{Identified failures and success factors in AgriDSS}

Many researchers have viewed the development of new AgriDSSs as possibilities for providing scientific knowledge and information to farmers with the aim of increasing sustainability and facilitate innovation (e.g., Fountas et al. 2005; McCown et al. 2009; Thorburn et al. 2011). During the last 30 years, research and development has produced a 
large number of AgriDSSs, but most of them have not been used appropriately in practice (e.g., Aubert et al. 2012; Eastwood et al. 2012; Korte et al. 2012, 2013; Mackrell et al. 2009; Matthews et al. 2008; McCown 2002; Rossi et al. 2014; Van Meensel et al. 2012). Aubert et al. (2012), for example, claim that factors influencing the adoption of innovations are tightly linked to work practices that are more complex than just the mere perspectives of technology acceptance or diffusion of innovations, while Fountas et al. (2005) point out that time requirement, lack of technical knowledge and cost are the most important impediments in the implementation of AgriDSS in PA. One central failure issue is the fact that researchers often focus on one specific area or problem, while the farmers must have a holistic view of the crop production with a wide range of problems (Rossi et al. 2014). Van Meensel et al. (2012) also point out that some AgriDSSs are too complex, and their terminology and functions are not adapted and are irrelevant to the intended users and their activities and context of use. The AgriDSSs are often developed as a result of technology push instead of a request grounded in a defined problem or an expressed need. A related explanation for this is that common technology acceptance models fail to take public resources, such as the environment, into account when analyzing the adoption of ICT systems (Melville 2010). Thus, there is an obvious gap between research and practice (e.g., Mackrell et al. 2009; McCown et al. 2009). Concerning the "problem of implementation", various explanations for the low adaption rate of AgriDSSs have been put forward, ranging from individual characteristics of farms, farmer's age and education level, resource availability, ease of use, and experienced usefulness to farmer's risk management attitude (e.g., Aubert et al. 2012; Pierpaoli et al. 2013) as well as high costs in investment and learning (e.g., Kutter et al. 2011). Two reasons that are explicitly stressed are how well the farmers perceive the PA technology as 'useful' and its 'ease of use' (e.g., Aubert et al. 2012; Pierpaoli et al. 2013). Lack of relevant standards and poor compatibility between different equipment, have for instance strong negative influence on the ease of use. The effort to develop user profiles of prospective end-users and their length of experience working with PA technology, as well as the length and frequency of using basic and advanced features of several AgriDSS, are factors that may have an impact on the ease of use. Hence, one major identified reason for the "problem of implementation" is the normative way of developing new technology without considerations of the actual needs of the end-users (e.g., Leeuwis 2004; McCown 2002, 2005; McCown et al. 2009).

The lack of knowledge about farmers' decision-making in practice is another reason for the failure of a transition toward sustainability. Existing research on how decisions are made, on which grounds and by which means, is based on overly rationalistic assumptions rather than on empirical data from decision-making processes in real-life settings (e.g., Gray et al. 2009; McCown 2005; Parker and Sinclair 2001; Öhlmér 2001; Öhlmér et al. 1998), though there are some exceptions (e.g., Bradford 2009; Lindblom and Lundström 2014; Lindblom et al. 2013). Success factors are, e.g., the level of involvement and trust that farmers' experience (Ljung and Källström 2013; Ljung et al. 2014), why over the last two decades it has become widely accepted that participatory approaches to sustainable land management may deliver additional benefits over non-participatory initiatives. The identified need to revise the study of decision-making of farmers toward more naturalistic decision-making models has taken initial steps. In other words, there seems to be a lack of knowledge concerning farmers' daily practices. The results from empirical studies of farmers' decision-making processes in practice show the potential usefulness of AgriDSS for agriculture (Lindblom and Lundström 2014; Lindblom et al. 2013).

Nevertheless, a well-designed AgriDSS is a useful tool for the ongoing transfer of scientific knowledge and "best practices" within the field of agriculture. Parker and 
Sinclair (2001), for example, claim that the single unifying predictor of success or failure of an AgriDSS is the extent to which users are involved and participate in design and development process. Moreover, Jakku and Thorburn (2010) as well as Van Meensel et al. (2012) stress the importance of participatory approaches for the successful development of AgriDSSs as well as the role and relevance of social learning by the stakeholders involved in the participatory AgriDSS development process. From this perspective, the lack of HCI, UCD and participatory approaches is the core of the identified "problems of implementation" of most AgriDSSs. Hence, there is a need to develop AgriDSS that simultaneously enables farmers to get access to the best knowledge available, while at the same time involving them in the design process of developing the AgriDSS. In other words, a sustainable agriculture is crucially dependent on sustainable ICT systems and UCD methodologies.

\section{Experiences from Sweden}

The technological development in PA has been rapid since the 90s, while a wide-ranging implementation and practical use of the technology has been much slower. Many farmers buy new machinery with built-in functions for variable measures and PA technology, without actually using it. This can be illustrated by the following quote from one of the farmer's involved in an ongoing project related to POS: "That is the situation nowadays ... you have a lot of technology, but you don't use it ... either is it a question of interest or knowledge ... often there is a lot of technology in a machine that you don't need ... and a lot of people do not use it ... far from”. In the late 1990s the Yara N-sensor was introduced on the Swedish market. Initially few farmers, some working as subcontractors, embraced the N-sensor technology; while the majority of farmers, advisers as well as the authorities remained rather passive, despite a continuous promotion of the technology in the farming press, exhibitions and by manufacturers. It had support from the manufacturers and distributors but there were few field experiments to secure reliability about the benefit of the $\mathrm{N}$-sensor technology from the start. Still the Yara N-sensor is an apparatus difficult to fully evaluate on individual fields without field experiments. Nevertheless, in 2015 most Swedish farmers have heard about the Yara N-sensor and during the season 2015, it has been estimated that approximately 130 Yara N-sensors are in practical use on Swedish farms. The growing condition was very favorable for cereals in 2015 with high yield potential and a high nitrogen demand to secure baking quality (i.e., protein content). Many farmers and advisor did not notice this increased N-demand until after harvest! However, fields fertilized with VRA based on $\mathrm{N}$-sensor showed higher $\mathrm{N}$-content both in wheat for milling and malting barley (pers. com. K Nissen Yara AB Sweden). The dominating Swedish flour mill claims that VRA of fertilizer is a necessity for production of wheat with the right quality for flour (http://www.kungsornen.se/).

The Yara N-sensor detects the status of nitrogen and biomass of plants by measuring canopy reflectance in parts of the red and near infrared electromagnetic spectrum (Link et al. 2002). The obtained spectral information is combined with a fertilizing algorithm which allows site-specific nitrogen fertilization within a field. Lammel et al. (2001) point out that the Yara N-sensor is valuable to avoid over- and under fertilization within a field resulting in increased yield, decreased lodging and more homogenous ripening. Other researchers accentuate that usage of the $\mathrm{N}$-sensor only have resulted in small differences in yield (Berntsen and Thomsen et al. 2006; Jørgensen et al. 2006) and Zillmann et al. (2006) 
point out that the $\mathrm{N}$-sensor technology work when nitrogen is the main growth-limiting factor. The usage of Yara N-sensor reduces nitrogen leaching if areas with lower requirements for nitrogen fertilization within the field can be identified (Delin and Stenberg 2014). Thus, the N-sensor technology could have benefits for farmers as well as for a more sustainable society in the long run. It has been recognized by stakeholders in the Swedish farming community that growers where crop quality and payment is strongly linked to the nitrogen content, such as malting barley and bread wheat, or where soil mineralization ability varies greatly for example due to high manure supply or variation in soil type, have the most important potential benefit of the N-sensor technology.

Generally speaking, most farmers realize that yield varies within a field as well as the amplitude of the variation can vary a lot between different fields. In theory, farmers should not have any problems to grasp the usefulness of the Yara N-sensor. Nevertheless many farmers do not use variable nitrogen application. The reasons could be higher costs, extra work, doubts of the credibility or cost-benefit. In fact, not even in special crops, for example in potatoes, where varied fertilization has been shown to provide a direct added value due to a better quality, the technology has been broader adapted.

In the early 2000 different assisted steering systems, such as auto steering, were introduced on the Swedish market. ICT systems as auto steering or guiding systems are intended to decrease overlaps, working hours, reduce energy consumption and facilitating new farming concepts such as controlled traffic. At least some of those described advantages are both easy to understand and become obvious just by watching the use of the technology in action, i.e., they provide momentary visual feedback in the fields. Farmers' interest has been comprehensive from the beginning and these PA technologies reached high popularity directly after being launched. The experience of the implementation of those straight forward PA applications is shared in Germany (Busse et al. 2014) as well as in Central and Northern Europe, the USA and Australia (EIP-Agri Focus group report 2015). It should be pointed out that compared to the Yara N-sensor, using a steering system also requires new technological knowledge by the farmer, but the two systems do demand slightly different kinds of decision making support. The Yara N-Sensor requires data input of expected yield and fertilizer need at the reference site, while the steering system only requires making an operative decision concerning the distance to the next track. A steering system in a tractor or harvester has a few obvious pedagogical benefits compared to the Yara $\mathrm{N}$-sensor in providing an understanding of the environmental and economic consequences of the actions done, the immediate effects that can be experienced while driving the tractor in the field. The performance of straight lines and the avoidance of double runs or missing rows are obvious and immediate results for the farmer. The farmer's immediate senses of the obtained advantages of the N-sensor compared with the assisted steering technologies thus differ. Payne et al. (2016) described nine extension strategies for technology adoption dependent on the kind of technology that would be adopted, from technology push to co-development strategies. Technologies that fit with the technology push strategy is characterized by non-complex issues, observable impacts, high compatibility and easy to implement, while more complex technologies without immediately observable benefits and difficulties in testing and implementation do instead need co-development strategies in order to be adopted. This is probably a central explanation to the differences between the adoptions of auto-steering systems compared with the Yara N-sensor.

An alternative to optimize the use of nitrogen is the AgriDSS named CropSAT (http:// www.cropsat.se/), developed by POS during the years 2013-2014. CropSAT uses satellite images for calculation of a vegetation index (Qi et al. 1994) for computation of VRA files for nitrogen fertilization in cereals. The vegetation index in CropSAT is correlated to 
measurements done with the Yara N-sensor (Söderström et al. 2015). In order to utilize CropSAT, the user starts the application on the internet, marks a field in a Google Earth application and the vegetation index from a chosen satellite image is calculated and shown on the marked field in Google Earth. To get a VRA file the user must decide on five levels of nitrogen amount related to the vegetation index (see Fig. 1). When the five levels are set a VRA file for the actual field can be calculated (see Fig. 2) and transferred to a spreader by an USB memory stick. The recommendation is that the user goes out into the field and verifies the nitrogen levels by measurements of absolute N-status with a so-called Spadmeter (https://www.konicaminolta.eu/en/measuring-instruments/products/colour-measure ment/chlorophyll-meter/spad-502plus/introduction.html) or just verifying the need of additional $\mathrm{N}$ with his or her own experience and knowledge about canopy greenness and N-status. During 2015 a high-fidelity prototype of CropSAT was available on the internet, free to use due to funding by the Swedish Board of Agriculture. Farmers and advisors have shown a considerable interest in CropSAT. CropSAT could be seen as an alternative to the $\mathrm{N}$-sensor, but with lower resolution. CropSAT enables direct observation of the within filed variation in canopy status which seems very interesting for the farmers taking part in ongoing project related to POS. So far, however, it has been pointed out by farmers that the procedure/process of setting the five levels of nitrogen amounts seems to be more complicated than expected, and needs to be studied further.

The above described PA technologies have had different impact on the Swedish market. The Yara N-sensor was launched in the 90s, represented an investment for the user in both learning and cost resulting in a new kind of decision making support equipment in order to governing fertilization. Steering systems was launched on the Swedish market in early 2000 and was rather quickly adapted broadly. This was probably due to the obvious advantages in cost reductions as well as easily and momentary produced instruction for VRA of N. It should be stressed that it is too early to evaluate the market penetration reply of the CropSAT technology. The fact that a significant number of farmers already have the technology needed to use the CropSAT technology, it is free of charge and free to use, funded and paid by Greppa Näringen (an advisory service funded by the Swedish government and EU through the Swedish Board of Agriculture) might be important aspects for its availability and impact. Hopefully it can contribute to lowering the barriers of entrance to VRA of $\mathrm{N}$ and have positive impact on Swedish farmers' usage of PA technology. Of major importance for the future impact is whether or not it is perceived as credible and useful for the farmers' work practices impact is whether or not it is perceived as credible and useful for the farmers' work practices and in comparison with the Yara N-sensor, and to what extent the CropSAT system is considered sustainable through design remains to be evaluated.

\section{Sustainable ICT: increased farmer participation through the application of HCI and UCD methodology}

Ideally, the endeavour for sustainable development should permeate all human activity, and since ICT is a pervading element in most people's lives (at least in wealthier countries), ICT plays an important role in this effort (Susi et al. 2015). The issue of designing ICT systems for human use, including a sustainability perspective, is receiving increased attention in ICT related research. In terms of the design and implementation of sustainable ICT solutions, the wording of the Brundtland definition has been reinterpreted to address 


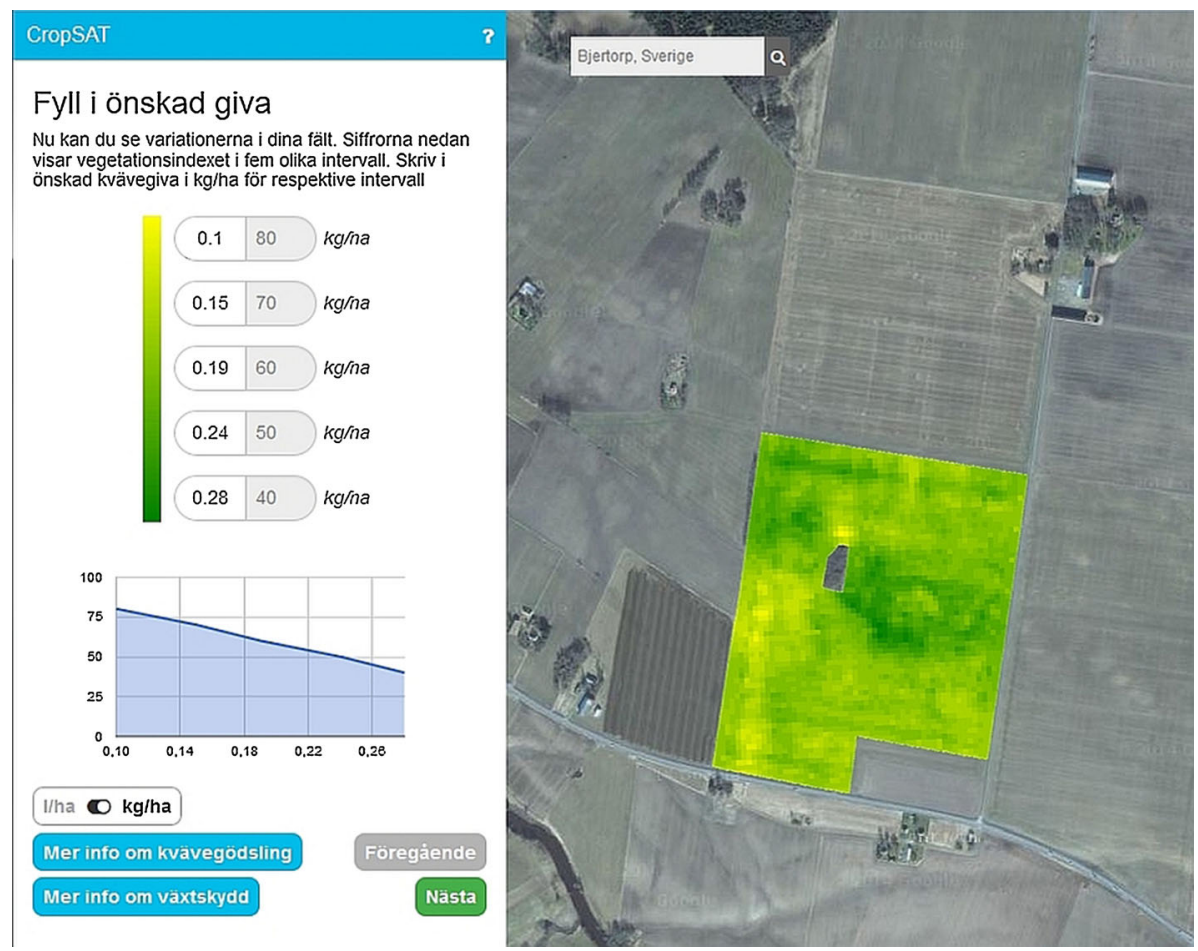

Fig. 1 Variation in vegetation index calculated by the AgriDSS CropSAT (http://www.cropsat.se) from a satellite image and visualized on a chosen field in Google Earth. Five levels of nitrogen application are set and can be used as a basis for calculations of a VRA

current challenges. A sustainable ICT system is, for example, characterized by longevity, simplicity, accessibility, responsiveness, and adaptability (Misund and Høiberg 2003). In particular, there is an increasing need for ICT studies with demonstrable impact on mitigating the threats to environmental sustainability (e.g., vom Brocke et al. 2013; Malhotra et al. 2013). The development and deployment of future sustainable agriculture requires acquisition, application and adaptation of knowledge, with the support of appropriate ICT systems (Dutta et al. 2014). Hence, the primary role of ICT systems within sustainable development is to create and communicate action possibilities for sense-making and sustainable practicing (Seidel et al. 2013).

\section{Sustainability through design}

To account for this need for sustainability in future deployments, Sustainable ICT Systems have been put forward as a new direction within the banner of ICT research, and for instance, e.g., in fields like HCI, and its subfields UCD, sustainable interaction design (SID) and sustainable design (SD) (e.g., DiSalvo et al. 2010; Huang et al. 2009; Håkansson and Sengers 2013; Issa and Isaias 2015; Pierce et al. 2013; Pink et al. 2013).

This paper directly acknowledge the dual link between environmental sustainability and ICT by addressing both (1) sustainability through design-how ICT can be used to promote more sustainable behaviors, and (2) sustainability in design-how sustainability can 


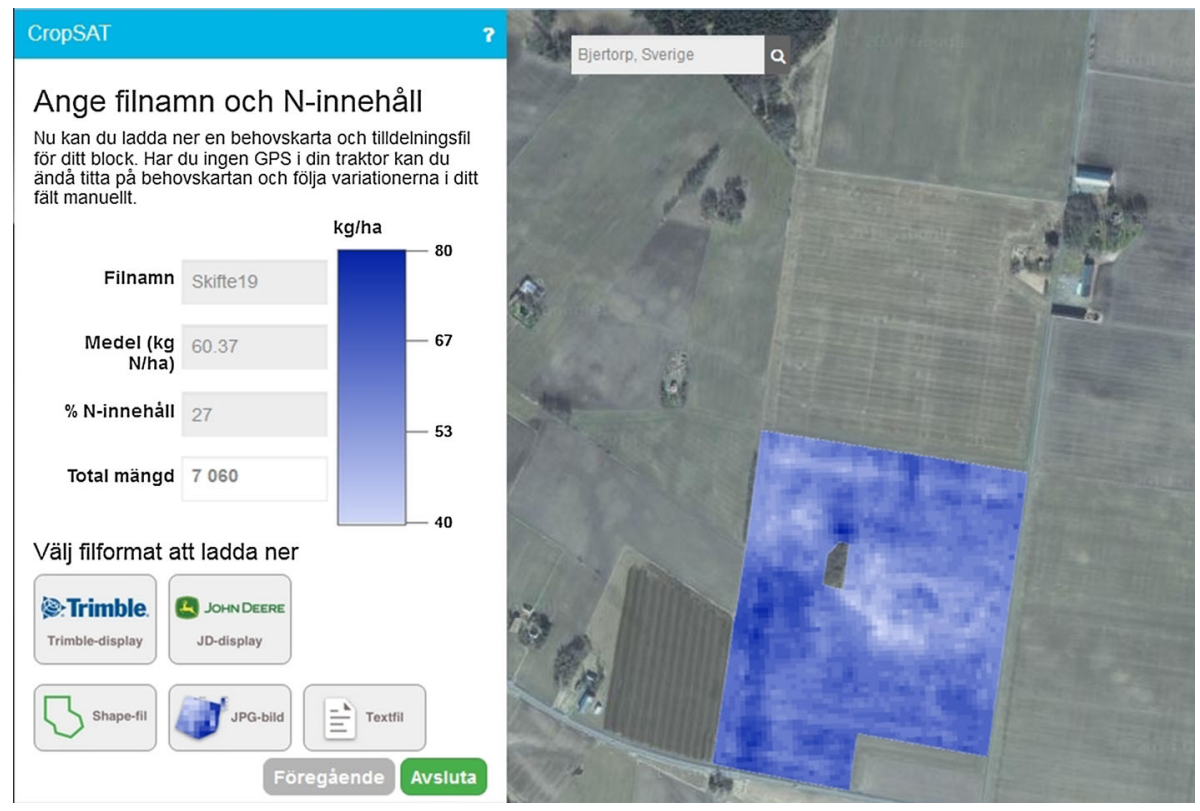

Fig. 2 The VRA file applied to a Google Earth map, ready to be saved on a USB memory stick and transferred to the spreader

be the governing principle of the design of the ICT systems themselves (Hanks et al. 2008; Mankoff et al. 2007). Hanks et al. (2008) point out the importance of sustainability for ICT design, focusing on SID which is the perspective that sustainability can and should have a central focus within HCI. The importance of considering sustainability within interaction design was put forward by Blevis (2007), and the focus in SID has since then centered on the linkage between environmental sustainability and ICT. However, Hanks et al. (2008) stress that it should be unavoidable for interaction designers to consider not only the ICT systems themselves from a perspective of environmental effects, but also the contexts of use and design for cultural alteration that can affect more sustainable human attitudes and behaviors.

In this paper the focus is on sustainability through design, and as pointed out by Susi et al. (2015), a number of different research genres regarding this perspective are labelled by DiSalvo et al. (2010). Firstly, they mention persuasive technologies, whose purpose is to influence the users to act in a more sustainable way, and such ICT systems are now in use in diverse domains, e.g., energy consumption, transportation habits healthcare, as well as education and training. Secondly, ambient awareness systems are based on so-called calm computing and ambient screen displays, with the purpose to increase the user's awareness of his or her current (un) sustainable behaviour. This can be brought about by making certain behaviour visible and a particular activity pattern promoting sustainability rewarding. Thirdly, SID focuses on fundamental reconsideration of ICT system design methodologies in HCI to tackle sustainability issues (e.g., DiSalvo et al. 2010; Issa and Isaias 2015). Within this genre, a turn to practice has evolved (Wakkary et al. 2013), which also is an emerging trend in HCI lately (Rogers 2012). Fourthly, the genre of formative user studies concerns an effort to understand users' ways of conceiving sustainability in their everyday life, and practices, as a means to creating new ICT design solutions 
(DiSalvo et al. 2010; Håkansson and Sengers 2013). Fifthly, pervasive and participatory sensing is concerned with the use of sensors that monitor and report the conditions in focus, with the intention of changing the conditions (DiSalvo et al. 2010).

In order to reduce the "problem of implementation" as well as the inter-related "gap of relevance" addressed in this paper, it has been argued by several authors that the design methodology of AgriDSSs needs to be user-centred, where the intended end-users actively participate throughout the whole design process. It should be pointed out that humans undergo activities that are contextual and it is the varieties in people's context that make the design of ICT systems challenging.

\section{HCI and UCD methodology}

The field of HCI is commonly characterized as; “... a discipline concerned with the design, evaluation and implementation of interactive computing systems for human use and with the study of major phenomena surrounding them" (The ACM SIGCHI group 1992). Generally speaking, HCI, as an interdisciplinary field, focuses on the various ways in which humans interact with ICT, and many textbooks have successfully highlighted the central principles in the analysis, design, development for achieving usability of these human-technology interactions (e.g., Benyon 2014; Dix et al. 2004; Hartson and Pyla 2012; Issa and Isaias 2015; Preece et al. 2002; Rogers et al. 2011). The interdisciplinary of HCI consists of a range of disciplines; including computer science, cognitive science, graphical design, industrial design, human factors, sociology and anthropology, resulting in a mix of science, engineering, and design aspects. It should be pointed out that designing usable ICT systems is not always straightforward, as the many poorly designed ICT systems show. One of the challenges of HCI design is to keep alongside of technological developments and to ensure that these are adapted for best possible human benefit. However, software developers often have poor understanding of HCI issues, and therefore it is of major importance that HCI specialists explicitly address their knowledge of how to think in terms of future users' needs, values and supportable tasks and how to translate that knowledge into a functional and usable ICT system, which fits well for the needs and capabilities of the people for whom they are intended (e.g., Hartson and Pyla 2012; Issa and Isaias 2015; Preece et al. 2002; Rogers et al. 2011).

To achieve the goals of HCI, a number of design methodologies can be utilized, which generally have the following characterizations in common: (1) user involvement throughout the whole design process, (2) integration of different kinds of disciplines and expertise, (3) conducting effective formative and summative usability evaluations, and (4) managing an iterative system design process (e.g., Benyon 2014; Dix et al. 2004; Hartson and Pyla 2012; Issa and Isaias 2015; Preece et al. 2002; Rogers 2012; Rogers et al. 2011).

Since the mid 1980s, several methodologies have become an important issue in the design of ICT systems, in order to achieve good usability. The concept of usability has been fairly defined in ISO 9241-11 (ISO 9241-11 1998), which describes an engineering approach where usability is specified in terms of measurable usability attributes and characterized as "the extent to which a product can be used by specified users to achieve specified goals with effectiveness, efficiency, and satisfaction in a specified context of use". However, good usability does not appear by itself, since it has to be systematically and consciously designed for. In order to integrate usability and to involve HCI professionals in ICT development, the need of design methodologies for usability is put forward by many scholars and practitioners. 
The interdisciplinary field of HCI research offers a large amount of interesting UCD methodologies, showing user involvement to be a critical factor in successfully developing ICT systems in general (Harris and Weistroffer 2009). The result of employing a UCD methodology when designing and developing an AgriDSS is a more efficient, satisfying and usable experience for the user, which is likely to increase user acceptance, learnability and confidence of the system (Hartwick and Barki 2001). Generally speaking, UCD may be described as a practice, craft, framework, philosophy, discipline, or a methodology for design by involving users in the design process, and integrating UCD with other ICT development activities (Andreasson et al. 2015). ISO 9241-210 (ISO 9241-210 2010) is a standard that provides guidance for the "human-centered design process for interactive systems". It acknowledges the standard for usability, and defines UCD from a more general perspective than the various developed UCD methodologies.

Generally, UCD methodologies consist of three major iterative phases, i.e., the analysis phase, the design phase, and the evaluation phase. Basically, the purpose of the analysis phase is to understand the need of the intended users as well as the context of use, while the design phase involves the creation of a conceptual design concept, the interaction pattern, the "look and feel" of the product, and prototyping to realize different design alternatives. The evaluation phase focuses on verification and refinement of the design solution (Andreasson et al. 2015). According to Andreasson et al. (2015), some common UCD methodologies are user-centered systems design (UCSD) (Gulliksen et al. 2003; Göransson et al. 2003), usability engineering (UE) (Faulkner 2000; Mayhew 1999), goal-directed design (GDD) (Cooper et al. 2007), and participatory design (PD) (Bjerknes et al. 1987). Briefly stated, UCSD is a method that focuses on usability through the entire ICT system life cycle. Gulliksen et al. (2003) addressed a lack of a shared definition for the approach and identified 12 key principles of UCSD. The principles are based on both theory and experience from software development projects and revolve around users and the understanding of their needs. The key principles emphasize a clear user focus with user involvement, iterative and incremental system development with early and continuous prototyping, and evaluations performed in the context of use. User-centered systems design consists of three major phases; requirements analysis, evolutionary systems development (which is both iterative and incremental), and implementation. Gulliksen et al. (2003) stress the importance of a well thought-out transition process where the introduction must be planned, where user education and training is performed as well as the need for necessary support and instruction manuals (for further details, see Gulliksen et al. 2003; Göransson et al. 2003).

Usability Engineering was first introduced by usability professionals, which used the term to refer to concepts and techniques for planning, achieving, and verifying objectives for system usability (Faulkner 2000; Mayhew 1999). The key idea of UE is to define measurable usability goals early in the ICT system design process and, with repeated assessment, ensure that they are achieved (Rosson and Carroll 2002). The method of UE is defined in the usability engineering lifecycle, which consists of three phases that describe a set of tasks and the order they should be applied in during an ICT development lifecycle (Mayhew 1999). The lifecycle is highly structured and contains several different tasks and techniques for the developers to perform in each of the lifecycle's three phases (for further details, see Mayhew 1999).

The GDD method is usually qualitative and anthropological, where ethnographic underpinnings to the process are noticeable. Cooper et al. (2007) describe that the initial phases focus on providing data about (actual or potential) end-users of the intended ICT system and to identify behavior patterns, which provides an understanding of the end- 
users' tasks, goals, and motivations. In the design phases, the designers first create the overall concept of the ICT system, its general design solution and interaction flow, before an increased focus on details and implementation occurs. Finally, the authors emphasize the importance of a supportive work environment in which the designers and the developers cooperate and support each other when making tradeoffs or adjusting the final ICT design solution (for further details, see Cooper et al. 2007).

Finally, a more radical UCD approach is the "Scandinavian model" of PD emerging within the system development field among a group of Scandinavian researchers who focused on the democratization of working life (Bjerknes et al. 1987). Participatory design as a design approach is characterized as attempting to actively engage all users and stakeholders (they all are seen as equal partners) in the ICT design process in order to achieve that the product designed fulfils their needs and is useful. Participatory design stresses the importance of processes and procedures of design and is more responsive to their stakeholders' and users' cultural, emotional, and way of working practices and learning (Bjerknes et al. 1987).

In sum, UCD and PD methods have the vision of insuring high usability, i.e., adapting the system to the 'end-users' and 'stakeholders' needs and goals which increase the possibility of satisfied users and AgriDSS success significantly. The final AgriDSS is not an end in itself; rather the system is a means towards the end of providing good usability, and for supporting the actual tasks for the intended users. Applying these UCD methods to the design of sustainable ICT systems, the question is how a digital artifact in form of an ICT system can be designed such that users will prefer sustainable behaviors to unsustainable ones.

\section{Sustainable HCI}

Sustainability is a complex issue and it presents challenges but also opportunities for ICT interventions, and it has been argued that the HCI community "embodies knowledge and expertise that will be crucial to addressing the design, interaction, and usage issues surrounding sustainable technologies and practice" (Huang et al. 2009). Thus, ICT-related research fields, have the potential to contribute to our common future by directing substantial research efforts towards sustainable development (Susi et al. 2015). As pointed out by Pierce et al. (2013) environmental sustainability has established itself as a mainstream concern for HCI since Blevis (2007) seminal paper in 2007. Since then, HCI researchers have begun to recognize that the complexity and apparent uncontrollability of working towards sustainability offers serious challenges to the current and traditional HCI approaches to solve problems. Contrary, Pierce et al. (2013) stress that this should not be faced as a problem at a first glance. Instead, it could be considered as an opportunity to understand the limits of HCI as currently constituted and as a way forward to further development and possibilities for the field of HCI.

The majority of work in sustainable HCI has so far focused on how to change individuals' attitude and behaviors to become less resource-intensive and be more aware of environmental and sustainability issues. This way of research has drawn mainly on theories and concepts from social psychology and behavioral economics (Pierce et al. 2013). According to Pierce et al. (2013) one recently identified methodological limitation is the overwhelming dependence in HCI research on individuals as the unit of analysis for design, development and evaluation. Instead, as they point out, recent work within sustainable HCI offers an alternative approach to sustainable HCI by shifting the unit of analysis from individual action to everyday practice. They highlight that this shift of focus 
and scope, to consider organizations and reorganizations of shared activities and routines rather than individual behaviours and general social values and norms, results in looking beyond isolated interactions between humans and computers and instead view them as necessary ingredients of practice rather than simply something that humans interact with (Pierce et al. 2013). Taking practice as the unit of analysis, it offers HCI researchers new ways to investigate the dynamics of (un)sustainability, generating understandings of the interactions between humans and other material artefacts that more fully capture the complexity of everyday practices as they are enacted and change over time (Pierce et al. 2013). As pointed out by Watson's commentary of the special issue on practice-oriented approaches to sustainable HCI (in DiSalvo et al. 2013), to consider different aspects of the potential relationship between practice theories and the role of design and HCI in creating future changes in everyday life can contribute to a socio-technical change towards better and greater sustainability.

The issue of sustainability has recently been incorporated into the new participative methodology for sustainable design (NPMSD) developed by Issa and Isaias (2015). They intend that the NPMSD should support designers when developing new ICT systems to paying more attention on sustainability in general, addressing both sustainability in design as well as sustainability through design, without explicitly referring to Hanks et al. (2008) and Mankoff et al. (2007). Briefly stated, NPMSD is an ambitious method and is divided into ten stages namely: usability evaluation; functionality testing, planning, analysis, design, maintenance, user participation, iteration, and content management systems. The design stage, for example, addresses six identified factors regarding sustainability, which are the following: design (e.g., easy to add new software and to recycle), safety (e.g., reducing carbon footprint, consumption and waste of resources), manufacture and energy (e.g., use less energy and raw materials), recycling (e.g., using recycled and renewable materials), efficiency (e.g., having long life), and social needs (e.g., having clean emissions and good ethical principles). The importance for HCI specialists to understand the impacts of their actions on the earth, particularly the ICT use, are stressed in NPMSD. Issa and Isaias (2015) aim to safeguard our planet by raising HCI specialists' awareness regarding their moral responsibility to create sustainable design for a sustainable future.

\section{Reducing the "problem of implementation"}

Some recent successful examples of active user-involvement in the design process of AgriDSSs are exemplified in the work by Jakku and Thorburn (2010) as well as Van Meensel et al. (2012). Jakku and Thorburn (2010) highlight the importance of involving stakeholders as active participants throughout the whole ICT design process. A central issue they address is the changed view on the agricultural innovation process, stressing the importance of viewing agricultural innovations as complex interactive processes of colearning and negotiation, in which social learning practices are fostered. The final report from the EIP-Agri focus group Precision Farming (2015) emphasizes the creation of frameworks where farmers, advisors, researchers and the industry cooperate to increase innovations in PA. In such frameworks, AgriDSS can function as a "discussion tools", facilitating the dialogue between different key stakeholders within agriculture, such as farmers, scientists, advisors, and extension officers. Moreover, Van Meensel et al. (2012) point out that decision-making in pig farming is considered as a typical case of the simultaneously improvement of productivity and the effort to reduce environmental pressure, primarily produced by nutrient emissions (Van Meensel et al. 2012). They identify some success factors in the PD approach of an AgriDSS named Pigs2win. The aim 
of Pigs2win was to develop an AgriDSS that is scientifically sound, usable in practice, and supported by the pig sector in the actual region. Critical success factors that affected the Pigs 2 win project include, flexibility, perceived usefulness, accessibility, credibility, maintenance and adaptability, and focus on the intended users. Central issues for the success of the participatory approach during the whole development process are: (1) selection of appropriate stakeholders and high level of transparency to the stakeholders, (2) constructive collaboration among stakeholders that resulted in active involvement and a consensus of common goals for the AgriDSS, and (3) a flexibility in the development process, respecting the available time and scope, but accepting adaptation during the process and not following a priori detailed road map (Van Meensel et al. 2012). As a result of using a participatory process, the stakeholders identified 14 outcomes that the AgriDSS should be able to handle properly, which then were digitally implemented in 12 features in Pigs2win. The result is an AgriDSS that allows for identifying farm-specific suboptimal KPIs (key performance indicators), and assessing aggregate economic and environmental effects of improving these KPIs. Van Meensel et al. (2012) stressed that the AgriDSS does not provide any direct advice on what concrete decision to make. This means, the actual decision is left for the intended user (advisor) to do, but the AgriDSS provides information on the KPIs that is useful in supporting the activities of pig farming via ICT support.

Summing up, UCD and PD methods in ICT system design stress the importance to understand the contexts in which the activities take place, getting to know the people involved, establishing a dialogue of mutual sharing of different perspectives, and working together to reach common goals. Additionally, Thorburn et al. (2011) emphasize that apart from increased adoption and acceptance of the developed AgriDSS, PD approaches seem to enact co-learning as a result of the development process. They stress that learning is a valuable process in increasing sustainability in agriculture, so that the application of AgriDSS in a social learning context may make a contribution to the global challenges faced by agriculture. They point out that the value of participatory development processes of AgriDSS as a co-learning process is an outcome that traditionally has not been appreciated enough by AgriDSS developers and one identified issue that is likely to tackle the challenges faced by agricultural sustainability.

\section{Some beginners' pitfalls in UCD/PD methods and some suggestions on how to reduce them}

Although there is convincing evidence in the scientific literature concerning the benefits of applying a PD approach in the development and design process of AgriDSSs, there are still some challenges that need to be addressed in practice. Ideally, it is recognized (Bjerknes et al. 1987; Marti and Bannon 2009) that the end-users should be regarded as equal partners in the development team, and being involved from the very beginning of the design and development process. Designers and end-users should be of equal importance, learning from each other in order to create a mutual understanding of the limitations and possibilities of the developing AgriDSS.

The development and design process of the POS network's AgriDSS for calculation of VRA files has begun and a high-fidelity prototype was presented during 2015. User participation to this point has been very limited, and the ambition is to introduce user participation in the upcoming iterative development, evaluation and implementation process. Precision agriculture Sweden intends to apply a UCD/PD approach in order to avoid the 
"problem of implementation" as well as the "gap of relevance". However, some doubtful comments for such an approach have been expressed among the team developing CropSAT, illustrated by the following utterances; "we can do it ourselves", "it takes a lot of time", and "we should not believe that the farmers always know". The POS development team has raised the following questions for the future design and development process of the AgriDSS:

- What information is needed?

- When is the information needed?

- Who needs it?

- Where is it needed?

- Why is it needed?

The expressed doubts are relevant from their perspective, and some necessary methodological support is available in the UCD methodologies (e.g., UCSD, GDD, UE, PD, and NPMSD) presented in "Sustainable HCI" section. They can serve as starting points for the continued design process. In so doing, a group of relevant stakeholders consisting of end-users such as farmers, advisors and some researchers will be recruited, and they will meet on a regular basis. Furthermore, the initial project members have also identified the need of a HCI specialist in the role of a user advocate/facilitator who aims to act as an intermediate link/coach between different participants in order to create a common ground and reach consensus within the newly established development team. Although the intention of introducing aspects from a UCD/PD approach is beneficial, for the technical development team consisting of researchers, there are some identified pitfalls to consider which are listed below:

- Non-familiarity with addressing usability work and specific work activities and processes in PD.

- General lack of knowledge concerning UCD methodology, and PD methods in particular.

- General lack of discussions of the usefulness of usability work during the analysis, design and evaluation phases as well as lack of practical experience of usability work.

- Lack of a common vocabulary in order to properly discuss usability and related design issues in the team as a whole.

- Lack of time for informing the new members of the implicit history of previous design and development decisions, resulting in insufficient transparency.

- Introducing new ways of working that aim to foster knowledge exchange and equal impact.

- If a facilitator/user advocate will not be recruited as a HCI specialist, who in the present team has the competence and skills to fulfill this important role?

Although the above list, at first glance, may be discouraging, it serves as an initial step to reduce the pitfalls, given the fact that they are identified and made explicit. The list provides a good starting point for the forthcoming work process in the technical development team, and its additional members (i.e., the intended end-users of their AgriDSS). Some actions that are being considered to reduce the pitfalls are:

- Inviting an external HCI specialist in usability work to introduce UCD/PD to POS members, aiming to reach acceptance for the UCD/PD approach by an introduction workshop. With a long experience of the "problem of implementation" of new ICT 
systems, the aim is that POS will begin to use this approach in future development processes.

- Recruiting farmers and advisors as end-users that are considered as early adopters and "willing and able" to participate in this kind of UCD/PD project.

- Choosing a user advocate/HCI specialist, with responsibility for mediating between end-users and technical developers that will lead the UCD/PD work activities. The central question is who that will be? Should the user advocate be an external consultant or should somebody from POS be responsible for this role and learn through apprenticeship during the UCD/PD process?

- Planning for the future design and evaluation work will be performed together with all members in the UCD/PD team, focusing on evaluating the prototype and also identifying and developing and designing additional, needed functionalities.

- Fitting the developed AgriDSS into the existing farming ICT system context, for example, farmers' plant production system or governmental system for extension services.

- Establishing a long term connection with a usability expert in order to manage conflicting collected user data and user opinions as well as functioning as a guide/coach in the development/learning process.

The intention is that the UCD/PD approaches presented above will initiate the turn of the tide for POS's future design and developmental work with PA technology, such as the exemplified AgriDSSs, in order to reduce the "problem of implementation". This way of working makes it easier to bridge the gap between theory and practice. The involved stakeholders in the POS project may reach an increased understanding of the "problem of implementation" through a social co-learning process. In the progressive development of the CropSAT technology, the design and development team is in the middle of a social colearning process themselves. Coming from different disciplines, with a broad spectrum of several kinds of experiences and knowledge, it has been recognized that some common concepts are used in slightly different ways, and subsequently the need for co-learning and negotiation is obvious. To conclude, this paper argues that applying a UCD/PD approach when developing an AgriDSS will lead to innovative and more applicable farm management practices which in the long run should increase sustainability in agriculture despite the addressed challenges.

\section{Discussion and conclusions}

It is argued in this paper that a sustainable intensification of agriculture is closely linked to our ability to interpret and apply the increasing amount of information generated in the agricultural system. But for farmers, who are the ones that finally make the decisions, the perceived relevance of this information as well as the applicability of introduced AgriDSS might not be as anticipated. This paper has mentioned different reasons for the so-called "problem of implementation", which is one challenge for sustainable intensification. It is conceptual and contributes by introducing sustainable ICT as a key approach for successful development of AgriDSS in the agricultural domain in general and in precision agriculture more specifically. By integrating different research fields the aim is to address some challenges when working towards sustainable intensification through PA, but also to the general discussion about emerging socio-technological systems in modern agriculture. 
In the context of agricultural sustainability, the role of learning in changing farming practices is obvious (Leeuwis 2004). The learning perspective is strengthened when applying more participatory approaches and focusing on involvement, especially when it takes place early in the development process. This is valid for most new practices, and it is not only a technical question of improving the usability and the ease of use. It also concerns building trust and stronger relations between the actors involved. The "problem of implementation" is therefore as much a reflection of a learning deficit as it is a question of not having relevant incentives to induce change.

Historically the discussion on implementation of new technologies and management concepts in agriculture has belonged to the tradition of knowledge transfer, i.e., there are predefined senders, intermediaries as well as receivers of knowledge, where knowledge is thought of as flowing in one predestined direction from science to practice (Leeuwis 2004) that Black (2000) labelled as the "technological fix". It should be noted however that despite raised critique of knowledge transfer models, there is still a need for access to reliable scientific knowledge (Ingram 2014).

In this paper, the assumption of "technological fixing" has been criticized, and instead a more sustainable trajectory that demands a changed perspective on different stakeholders' roles and importance for the development of new knowledge and practices has been proposed. This is in line with Hoffmann et al. (2007), who advocate that farmers could be regarded as experts in their own domain, and as such they cannot easily be replaced by other persons. This stance is properly aligned with the view of end-users in HCI, where users are considered as experts of their work practices, and one of the major challenges in developing useful ICT systems is to grasp their tacit knowledge "in the wild" (e.g., Rogers 2012). Nowadays it is obvious for many researchers that farmers' own knowledge, grounded in experience of their complex life situations or "life-world", must be carefully considered in the development process of agricultural innovations (e.g., Eastwood et al. 2012; Lindblom and Lundström 2014; Lindblom et al. 2013; Marra et al. 2003). This shift in perspective of the "problem of implementation", from persuasion of farmers to cocreation of knowledge, technology and meaning, develops agriculture in a desirable trajectory. It is the individual farmers that make a decision to implement or refrain to use an innovation as long as they are not forced by legislation or motivated/economically dependent due to subsidies. Farmers' decision making processes are complex situational practices that need to be acknowledged within its social-technical context, using an alternative to the historical, normative model framework (e.g., Rogers 1995).

This paper wants to stress that the call for more participatory approaches does not mean that one should be naïve when it comes to the challenges facing how to organize and facilitate participatory processes, neither the question whose knowledge counts in these design processes that Black (2000) labelled as the "participation fix". There is still a need to provide for active participation by farmers in agricultural research and development processes. Consequently, Ingram's (2014) view that the territory in-between the two ends of the spectrum of the top-down knowledge transfer, i.e., the "technological fix" based on scientific knowledge and the bottom-up participatory approaches, i.e., the "participatory fix", drawing on farmers' own practices and local knowledge, is of most interest.

There are no predefined answers to these questions concerning how to handle the territory in-between; instead it is by learning-by-doing that desirable and feasible methods will emerge. Nevertheless, inviting stakeholders with different perspectives and competences is important for a socially robust end result, as well as a capacity to manage conflicts that can arise in the negotiation between these different views. This also implies that all actors involved have something to learn from each other. The main purpose for 
development of new AgriDSSs in PA is to change current practices to a more sustainable farming. Therefore, in an agricultural context of uncertainty and unpredictability continuous learning processes for everybody involved are required that incorporate new information, knowledge and experience. Accordingly, farmers and other relevant stakeholders and institutions have to change established frames of mind and ways of acting. This approach is qualitatively different from minor adjustments in certain conventional farming behaviours, since it rather enables an adaption of transformal farming practices based on alternative norms and values cultivating a sustainable agriculture.

Indeed, this is a truly transdisciplinary and social learning approach to the development of the next generation AgriDSS, which does not work by itself, but there is not any proper alternative to reach the ambitious goals. We are living in the middle of an exciting time, where sustainable farming systems are dependent on the quality of ICT, and where ICT must integrate a sustainability perspective. If so the two domains will reinforce each other in the development of sustainable farming practices. On the one hand, Aubert et al. (2012), for example, argue the agricultural sector has received far less attention in order to improve decision making and ICT research, although its importance, compared to the manufacturing and financial sectors that have received much more interest, which is somewhat surprising given its critical role in securing food supply globally, environmental issues and the strong potential contribution of ICT in agriculture. On the other hand, Rogers (2012), for example, highlights that many HCI researchers are very motivated by addressing societal goals, but there is the tension of trying to help a community through "developing" and implementing appropriate ICT as opposed to trying to make contributions to the HCI field to get published. Rogers (2012) provides a striking example where a team of HCI researchers can spend long periods of time to set up a new ICT infrastructure that locally supports a more efficient water supply only for it not to be considered methodologically rigorous enough to deserve publication in the $\mathrm{CHI}$ community.

Indeed, the HCI community is beginning to learn to be more open and transdisciplinary, which in the future ultimately will demonstrate how to develop user experiences and human augmentation that covers a range of human values that can make an impact on society, at many levels. As presented in this paper, ICT can contribute significantly to longterm sustainable development. Thus, several competences and scientific disciplines need to act in concert to help develop a sustainable development of agriculture.

Acknowledgements We wish to thank all participants in the on-going project in POS as well as assistant professor Beatrice Alenljung and associate professor Göran Falkman. This paper is financially supported by the thematic research program Biological Soil Mapping (BioSoM) at the NJ-faculty, Swedish University of Agricultural Sciences.

Open Access This article is distributed under the terms of the Creative Commons Attribution 4.0 International License (http://creativecommons.org/licenses/by/4.0/), which permits unrestricted use, distribution, and reproduction in any medium, provided you give appropriate credit to the original author(s) and the source, provide a link to the Creative Commons license, and indicate if changes were made.

\section{References}

ACM SIGCHI Group (1992). Curricula for human-computer interaction. http://old.sigchi.org/cdg/cdg2. html\#2_1. Last accessed [2015112704].

Alenljung, B. (2008). Envisioning a future decision support system for requirements engineering: A holistic and human-centred perspective. Doctoral Thesis, Department of Computer and Information Science, Linköping University, Sweden, Thesis No. 1155. 
Andreasson, R., Lindblom, J., \& Thorvald, P. (2015). Towards an increased degree of usability work in organizations. Procedia Manufacturing, 3, 5739-5746.

Aubert, B. A., Schroeder, A., \& Grimaudo, J. (2012). IT as enabler of sustainable farming: An empirical analysis of farmers' adoption decision of precision agriculture technology. Decision Support Systems, 54, 510-520.

Benyon, D. (2014). Designing interactive systems: A comprehensive guide to HCI, UX and interaction design. Harlow: Pearson Education Limited.

Berntsen, J., Thomsen, A., Schelde, K., Hansen, O. M., Knudsen, L., Broge, N., et al. (2006). Algorithms for sensor-based redistribution of nitrogen fertilizer in winter wheat. Precision Agriculture, 7(2), 65-83.

Bjerknes, G., Ehn, P., \& Kyng, M. (Eds.). (1987). Computers and democracy-A Scandinavian challenge. Aldershot, UK: Avebury.

Black, A. W. (2000). Extension theory and practice: A review. Australian Journal of Experimental Agriculture, 40, 493-502.

Blevis, E. (2007). Sustainable interaction design: Invention \& disposal, renewal \& reuse (pp. 503-512). In: Proceedings of $\mathrm{CHI}$ 2007, New York: ACM.

Boström, M. (2012). A missing pillar? Challenges in theorizing and practicing social sustainability. Sustainability: Science, Practice, \& Policy, 8(12), 3-14.

Bradford, L. E. A. (2009). A complicated chain of circumstances: Decision making in the New Zealand wool supply chains. Doctoral Dissertation, Christchurch, Lincoln University, New Zealand.

Busse, M., Doernberg, A., Siebert, R., Kuntosch, A., Schwerdtner, W., König, B., et al. (2014). Innovation mechanisms in German precision farming. Precision Agriculture, 15(4), 403-426.

Caron, P., Biénabe, E., \& Hainzelin, E. (2014a). Making transition towards ecological intensification of agriculture a reality: The gaps in and the role of scientific knowledge. Sustainability Governance and Transformation, 8, 44-52.

Caron, P., Biénabe, E., \& Hainzelin, E. (2014b). Making transition towards ecological intensification of agriculture a reality: The gaps in and the role of scientific knowledge. Current Opinion in Environmental Sustainability, 8, 44-52.

Cerf, M., Jeuffroy, M.-H., Prost, L., \& Meynard, J.-M. (2012). Participatory design of agricultural decision support tools: Taking account of the use situations. Agronomical Sustainable Development, 32, 899-910.

Cooper, A., Reimann, R., \& Cronin, D. (2007). About face 3: The essentials of interaction design. Indianapolis: Wiley.

Daly, H. E. (1990). Toward some operational principles of sustainable development. Ecological Economics, 2(1), 1-6.

Delin, S., \& Stenberg, M. (2014). Effect of nitrogen fertilization on nitrate leaching in relation to grain yield response on loamy sand in Sweden. European Journal of Agronomy, 52(B), 291-296.

DiSalvo, C., Redström, J., \& Watson, M. (2013). Commentaries on the special issue on practice-oriented approaches to sustainable HCI. ACM Transactions on Computer-Human Interaction (TOCHI), 20(4), 26.

DiSalvo, C., Sengers, P. \& Brynjarsdóttir, H. (2010). Mapping the landscape of sustainable HCI (pp. 1975-1984). In: Proceedings of the SIGCHI conference on human factors in computing systems. New York: ACM.

Dix, A., Finlay, J., Abowd, G., \& Beale, R. (2004). Human-computer interaction. Harlow: Pearson Education.

Dutta, R., Morshed, A., Aryal, J., D’Este, C., \& Das, A. (2014). Development of an intelligent environmental knowledge system for sustainable agricultural decision support. Environmental Modelling and Software, 52, 264-272.

Eastwood, C. R., Chapman, D. F., \& Paine, M. S. (2012). Networks of practice for co-construction of agricultural decision support systems: Case studies of precision dairy farms in Australia. Agricultural Systems, 108, 10-18.

EIP-Agri Focus group on precision farming final report 2015 (2015) https://ec.europa.eu/eip/agriculture/ sites/agri-eip/files/eip-agri_focus_group_on_precision_farming_final_report_2015.pdf. Last accessed [151124].

EU SCAR. (2012). Agricultural knowledge and innovation systems in transition. Brussels: EU.

Faulkner, X. (2000). Usability engineering. London: Macmillan Press Ltd.

Fountas, S., Blackmore, S., Ess, D., Hawkins, S., Blumhoff, G., Lowenberg-Deboer, J., et al. (2005). Farmer experience with precision agriculture in Denmark and the US Eastern Corn Belt. Precision Agriculture, 6, 121-141.

Garnett, T., Appleby, M. C., Balmford, A., Bateman, I. J., Benton, T. G., Bloomer, P., et al. (2013). Sustainable intensification in agriculture: Premises and policies. Science, 341(6141), 33-34. 
Göransson, B., Gulliksen, J., \& Boivie, I. (2003). The usability design process-Integrating user-centered system design in the software development process. Software Process Improvement and Practice, 8 , 111-131.

Gray, D. I., Parker, W. J., \& Kemp, E. (2009). Farm management research: A discussion of some of the important issues. Journal of International Farm Management, 5(1), 1-24.

Gulliksen, J., Göransson, B., Boivie, I., Blomkvist, S., Persson, J., \& Cajander, А. (2003). Key principles for user-centred system design. Behaviour \& Information Technology, 22(6), 397-409.

Håkansson, M. \& Sengers, P. (2013). Beyond being green (pp. 2725-2734). In: Proceedings of the SIGCHI conference on human factors in computing system. New York: ACM.

Halberg, N., Panneerselvam, P., \& Treyer, S. (2015). Eco-functional intensification and food security: Synergy or compromise? Sustainable Agriculture Research, 4(3), 126-139.

Hanks, K., Odom, W., Roedl, D. \& Blevis, E. (2008). Sustainable millennials: Attitudes towards sustainability and the material effects of interactive technologies. In: Proceedings of CHI 2008, New York: ACM.

Harris, M. A., \& Weistroffer, H. R. (2009). A new look at the relationship between user involvement in systems development and system success. Communications of the Association for Information Systems, 24(1), 739-756.

Hartson, R., \& Pyla, P. S. (2012). The UX book: Process and guidelines for ensuring a quality user experience. Amsterdam, The Netherlands: Morgan Kaufmann.

Hartwick, J., \& Barki, H. (2001). Communication as a dimension of user participation. IEEE Transactions on Professional Communication, 44(1), 21-36.

Hoffmann, V., Probst, K., \& Christinck, A. (2007). Farmers and researchers: How can collaborative advantages be created in participatory research and technology development? Agriculture and Human Values, 24(3), 355-368.

Huang, E. M., Blevis, E., Mankoff, J., Nathan, L. P., \& Tomlinson, B. (2009). Defining the role of HCI in the challenges of sustainability. CHI'09 extended abstracts on human factors in computing systems (pp. 4827-4830). New York: ACM.

Ingram, J. (2014). Agricultural adaptation to climate change: New approaches to knowledge and learning. In J. Fuhrer \& P. J. Gregory (Eds.), Climate change impact and adaptation in agricultural systems (pp. 253-270). Wallingford: CABI.

ISO 9241-11. (1998). Guidance on usability. Geneva, Switzerland: International Organization for Standardization.

ISO 9241-210. (2010). Human-centred design for interactive systems. Geneva, Switzerland: International Organization for Standardization.

Issa, T., \& Isaias, P. (2015). Sustainable design: HCI, sustainability and environmental concerns. London: Springer.

Jakku, E., \& Thorburn, P. J. (2010). A conceptual framework for guiding the participatory development of agricultural decision support systems. Decision Support Systems, 103, 675-682.

Jørgensen, R. N., Hansen, P. M., \& Bro, R. (2006). Exploratory study of winter wheat reflectance during vegetative growth using three-mode component analysis. International Journal of Remote Sensing, 27, 919-937.

Kerr, D. (2004). Factors influencing the development and adoption of knowledge based decision support systems for small, owner-operated rural business. Artificial Intelligence Review, 22, 127-147.

Korte, M., Lee, K. \& Fung, C.C. (2012). Sustainability in information systems: Requirements and emerging technologies (pp. 481-485). In: Proceedings 2012 international conference on innovation, management and technology research (ICIMTR2012). IEEE.

Korte, M., Lee, K., \& Fung, C. C. (2013). Evolving IT management frameworks towards a sustainable future. In H. Linger et al. (Eds.), Building sustainable information systems (pp. 271-284). New York: Springer.

Kutter, T., Tiemann, S., Siebert, R., \& Fountas, S. (2011). The role of communication and co-operation in the adoption of precision farming. Precision Agriculture, 12(1), 2-17.

Lammel, J., Wollring, J., \& Reusch, S. (2001). Tractor based remote sensing for varaible fertilizer application. In W. J. Horst et al. (Eds.), Plant nutrition-Food sustainability in agro-ecosystems. Dordrecht: Kluwer.

Leeuwis, C. (with contributions by A. van den Ban). (2004). Communication for rural innovation: Rethinking agricultural extension. Oxford: Blackwell Science.

Lindblom, J. \& Lundström, C. Lantbrukares beslutsfattande och lantbruksrådgivning-en förstudie. [In Swedish] (Farmers' decision-making and extension services - a pilot project). (2014). Department of Soil and Environment, Report Nr 15:2014, Swedish University of Agricultural Sciences. ISBN 978-91576-9263-4. 
Lindblom, J., Rambusch, J., Ljung, M. \& Lundström, C. (2013). Decision-making in agriculture-Farmers' lifeworld in theory and practice. 21st European Seminar on Extension Education (ESEE13).

Link, A., Panitzki, M. \& Reusch, S. (2002). Hydro N-sensor: Tractor-mounted remote sensing for variable nitrogen fertilization. In P. C. Robert (Ed.), Proceedings of 6th international conference on precision agriculture (pp. 1012-1018). ASA/CSSA/SSSA (published on CD).

Ljung, M., Fredricsson, M., Backman, C., \& Tshibanda, P. (2014). Rural regions 2020. Capacity building for sustainable development in rural areas. Project description. Skara: SLU.

Ljung, M., \& Källström, H. N. (2013). Miljöåtgärder $i$ samverkan. Jönköping: Jordbruksverket.

Mackrell, D., Kerr, D., \& von Hellens, L. (2009). A qualitative case study of the adoption and use of an agricultural decision support system in the Australian cotton industry: The socio-technical view. Decision Support Systems, 47(2), 143-153.

Malhotra, A., Melville, N., \& Watson, R. (2013). Spurring impactful research on information systems for environmental sustainability. MIS Quarterly, 37(4), 1265-1274.

Mankoff, J., Blevis, E., Borning, A., Friedman, B., Fussel, S. R., Hasbrouck, J., et al. (2007). Environmental sustainability and interaction. CHI'07 extended abstracts on human factors in computing system (pp. 2121-2124). New York: ACM.

Marra, M., Pannell, D. J., \& Abadi Ghadim, A. (2003). The economics of risk, uncertainty and learning in the adoption of new agricultural technologies: Where are we on the learning curve? Agricultural Systems, 75(2-3), 215-234.

Marti, P., \& Bannon, L. J. (2009). exploring user-centred design in practice: Some caveats. Knowledge, Technology \& Policy, 22(1), 7-15.

Măruşter, L., Faber, N. R., Jorna, R., \& van Haren, R. (2008a). Analysing agricultural users' patterns of behaviour. Agricultural Systems, 98, 159-166.

Măruşter, L., Faber, N. R., \& Peters, K. (2008b). Sustainable information systems. Journal of Systems and $I T, 10(3), 218-231$.

Matthews, K. B., Schwarz, G., Buchan, K., Rivington, M., \& Miller, D. (2008). Wither agricultural DSS? Computers and Electronics in Agriculture, 61(2), 149-159.

Mayhew, D. J. (1999). The usability engineering lifecycle-A practitioneŕs handbook for user interface design. San Francisco: Morgan Kauffman.

McCown, R. L. (2002). Changing systems for supporting farmers' decisions: Problems, paradigms, and prospects. Agricultural Systems, 74(1), 179-220.

McCown, R. L. (2005). New thinking about farmer decision makers. In J. L. Hatfield (Ed.), The farmer's decision: Balancing economic successful agriculture production with environmental quality (pp. 11-44). Ankeny, IA, USA: Soil and Water Conservation Society.

McCown, R. L., Carberry, P. S., Hochman, Z., Dalgliesh, N. P., \& Foale, M. A. (2009). Re-inventing modelbased decision support with Australian dryland farmers: Changing intervention concepts during 17 years of action research. Crop and Pasture Science, 60(11), 1017-1030.

Melville, N. P. (2010). Information systems innovation for environmental sustainability. MIS Quarterly, $34(1), 1-21$.

Misund, G. \& Høiberg, J. (2003). Sustainable information technology for global sustainability. In: Proceedings of the 3rd international symposium on digital earth, Czech Republic.

Öhlmér, B. (2001). Analytic and intuitive decision making-Swedish farmers' behaviour in strategic problem solving. In: Proceedings of the third EFITA conference. Montpellier: ENSAM.

Öhlmér, B., Olson, K., \& Brehmer, B. (1998). Understanding farmers' decision making processes and improving managerial assistance. Agricultural Economics, 18, 273-290.

Parker, C., \& Sinclair, M. (2001). User-centred design does make a difference: The case of decision support systems in crop production. Behaviour \& Information Technology, 20(6), 449-460.

Payne, T. A., Turner, J. A., Rijswijk, K., McDermott, A. K., \& Wakelin, R. D. N. (2016). Informing extension project design: The right tool for the work. Hill County-Grassland Research and Practice Science, 16, 33-38.

Pierce, J., Strengers, Y., Sengers, P., \& Bødker, S. (2013). Introduction the special issue on practice-oriented approaches to sustainable HCI. ACM Transactions on Computer-Human Interaction (TOCHI), 20(4), 20.

Pierpaoli, E., Carli, G., Pignatti, E., \& Canavari, M. (2013). Drivers of precision agriculture technologies adoption: A literature review. Procedia Technology, 8, 61-69.

Pink, S., Mackley, K. L., Mithchell, V., Hanratty, M., Escobar-Tello, C., Bhamra, T., et al. (2013). Applying the lens of sensory ethnography to sustainable HCI. ACM Transactions on Computer-Human Interaction (TOCHI), 20(4), 25.

Preece, J., Rogers, Y., \& Sharp, H. (2002). Interaction design: Beyond human-computer interaction. New York: Wiley. 
Qi, J. G., Chehbouni, A., Huete, A. R., Kerr, Y. H., \& Sorooshian, S. (1994). A modified soil adjusted vegetation index. Remote Sensing of Environment, 48(2), 119-126.

Rogers, E. (1995). Diffusion of innovation (5th ed.). New York: Free Press.

Rogers, Y. (2012). HCI theory: Classical, modern, and contemporary. San Rafael: Morgan \& Claypool.

Rogers, Y., Sharp, H., \& Preece, J. (2011). Interaction design: Beyond human-computer interaction. Hoboken, NJ, USA: John Wiley.

Rossi, V., Salinari, F., Poni, S., Caffi, T., \& Bettati, T. (2014). Addressing the implementation problem in agricultural decision support systems. Computers and Electronics in Agriculture, 100, 88-99.

Rosson, M. B., \& Carroll, J. M. (2002). Usability engineering: Scenario-based development of humancomputer interaction. San Francisco: Morgan Kaufmann.

Seidel, S., Recker, J. C., \& vom Brocke, J. (2013). Sensemaking and sustainable practicing. MIS Quarterly, 37(4), 1275-1299.

Söderström, M., Stadig, H., Nissen, K. \& Piikki, K. 2015. CropSAT: Kväverekommendationer och grödstatuskartering inom fält genom en kombination av satellitdata och N-sensorer. [In Swedish] (CropSAT: Nitrogen recommendations and crop status mapping within field by a combination of satellite data and N-sensors). Department of Soil and Environment, Precisionsodling Sverige, Report Nr: 36, Swedish University of Agricultural Sciences. ISSN: 1652-2826.

Susi T., Lindblom, J. \& Alenljung, B. (2015). Promoting sustainability: Learning new practices through ICT. In O. Lundwall, P. Häkkinen, T. Koschmann, P. Tchounikine and S. Ludvigsen (Eds.), CSCL 2015: Exploring the material conditions of learning: Conference Proceedings (pp. 743-744). Sweden: International Society of the Learning Sciences.

Thagard, P., \& Shelley, C. P. (1997). Abductive reasoning: Logic, visual thinking, and coherence. In Dalla et al. (Eds.), Logic and scientific methods. The Netherlands: Springer.

Thorburn, P. J., Jakku, E., Webster, A. J., \& Everingham, Y. L. (2011). Agricultural decision support system facilitating co-learning. International Journal of Agricultural Sustainability, 9(2), 322-333.

Van Meensel, J., Lauwers, L., Kempen, I., Dessein, J., \& van Huylenbroeck, G. (2012). Effect of a participatory approach on the successful development of agricultural decision support systems: The case of Pigs2win. Decision Support Systems, 54(1), 164-172.

vom Brocke, J., Watson, R., Dwyer, C., Elliot, S., \& Melville, N. (2013). Green information systems: Directives for the IS discipline. Communications of the Association for Information Systems, 33(30), 509-520.

Wakkary, R., Desjardins, A., Hauser, S., \& Maestri, L. (2013). A sustainable design fiction. ACM Transactions on Computer-Human Interaction (TOCHI), 20(4), 23.

World Commission on Environment and Development. (1987). Our common future. Oxford: Oxford University Press.

Zillmann, E., Graeff, S., Link, J., Batchelor, W. D., \& Claupein, W. (2006). Assessment of cereal nitrogen requirements derived by optical on-the-go sensors on heterogeneous soils. Agronomy Journal, 98(3), $682-690$. 